\title{
Pathologic Stage III HPV-Mediated (p16- Positive) Oropharyngeal Carcinoma AJCC v8
}

National Cancer Institute

\section{Source}

National Cancer Institute. Pathologic Stage III HPV-Mediated (p16-Positive)

Oropharyngeal Carcinoma A/CC v8. NCI Thesaurus. Code C132900.

Stage III includes: (T3, N2, M0); (T4, N2, M0). T3: Tumor larger than $4 \mathrm{~cm}$ in greatest dimension or extension to lingual surface of epiglottis. T4: Moderately advanced local disease. Tumor invades the larynx, extrinsic muscle of tongue, medial pterygoid, hard palate, or mandible or beyond. Mucosal extension to lingual surface of epiglottis from primary tumors of the base of the tongue and vallecula does not constitute invasion of the larynx. N2: T umor with metastasis in more than four lymph nodes. M0: No distant metastasis. (AJCC 8th ed.) 